\title{
Preliminary Study On The Development Of Sulfonated Graphene Oxide Membranes As Potential Novel Electrolytes For PEM Fuel Cells
}

\author{
S. Latorrata ${ }^{\mathrm{a}}$, A. Basso Peressut ${ }^{\mathrm{a}}$, Paola Gallo Stampino ${ }^{\mathrm{a}}$, C. Cristiani ${ }^{\mathrm{a}}$ and G. Dotelli ${ }^{\mathrm{a}}$ \\ ${ }^{a}$ Department of Chemistry, Materials and Chemical Engineering, Politecnico di Milano, \\ piazza Leonardo da Vinci, 32, 20133 Milan, Italy
}

\begin{abstract}
Innovative graphene oxide (GO)-based self-assembling membranes have been prepared in order to study their possible application in PEMFCs as a solid proton-conducting electrolyte alternative to Nafion ${ }^{\circledR}$. Firstly, a pure GO membrane has been produced as a benchmark, then it has been sulfonated with different quantities of sulfuric acid and characterized by using several techniques: Fourier transformed infrared spectroscopy (FTIR), thermogravimetric analysis (TGA), optical microscopy $(\mathrm{OM})$, water uptake (WU) and ion exchange capacity (IEC). On the basis of IEC measurements, the corresponding degree of sulfonation was calculated. Preliminary impedance spectroscopy measurements have been also performed in order to obtain conductivity of the membranes and compare it to the one of a commercial Nafion membrane. A relation between IEC, degree of sulfonation and conductivity was found and the sulfonated membrane prepared with an acid/GO molar ratio of 20 showed the best results.
\end{abstract}

\section{Introduction}

Proton exchange membrane fuel cells (PEMFCs) are regarded as one of the most promising devices for sustainable energy production due to several attractive features: simple, compact and modular design, quick start up time and adaptability for both portable and stationary applications; furthermore, they encompass a promise of high efficiency, low to zero emissions and high power density, as well as low cost and long life, due to the absence of moving parts (1-3). One of the key components of PEMFCs is the ionomer membrane, which must be able to efficiently conduct protons while preventing fuel crossover. The current state-of-the-art membrane material is DuPont's Nafion $^{\oplus}$, a perfluorosulfonic ionomer that exhibits superior and still unmatched properties, such as excellent proton conductivity (> $0.1 \mathrm{~S} / \mathrm{cm}$ under humidified conditions), long-term performance (over 60000 hours), good gas separation and appreciable chemical, mechanical and thermal stability (4-7). However, Nafion ${ }^{\circledast}$ has a high cost and shows a significant loss of performance at low relative humidity $(<50 \%)$ and at temperatures higher than $80{ }^{\circ} \mathrm{C}$, mainly because of membrane dehydration and mechanical degradation. Nonetheless, operation at high temperature $\left(>100{ }^{\circ} \mathrm{C}\right)$ would be undoubtedly beneficial in that it allows an easier water management (gaseous byproducts) and to achieve much higher energy efficiencies at lower usage of Pt catalyst, resulting in minor costs (8-12). Therefore, extensive research has been devoted to developing viable alternatives to Nafion $^{\circledR}$ for high temperature and low humidity 
operation. Among the possible approaches, graphene oxide (GO) has gained interest for the production of both freestanding $(2,4,5,13)$ and hybrid membranes. The latter may be still based on a Nafion matrix $(6,8-11,14-16)$ or on a different kind of ionomer, such as sulfonated poly(ether ketones) (7, 12, 17-21), sulfonated poly(ether sulfones) (22-25) and other sulfonated polymers $(12,26,27)$. The common thread in the choice of the polymer matrix will be a good proton conducting ability coupled with mechanical stability and low gas permeability.

GO is an excellent candidate for membrane preparation owing to its high surface area, excellent mechanical properties and to the presence of oxygen-containing hydrophilic functional groups, which enhance water retention and provide an excellent environment for proton conduction. However, the use of pristine GO presents some critical issues, such as the low performance and durability of stand-alone membranes $(2,5)$, with the destruction of GO layers or the loss of proton-conducting groups at high temperature, or the non-optimal interaction with the polymer matrix in the case of hybrids, responsible for a decrease in conductivity $(7,20,27)$. Hence, the properties of GO may be improved by functionalizing it with different acid groups more tightly bound to its layers $(3,8,10$, 13, 27). Extensive studies are particularly dedicated to the introduction of sulfonic acid groups $\left(-\mathrm{SO}_{3} \mathrm{H}\right)$, analogous to those of $\mathrm{Nafion}^{\circledR}$ and of other sulfonated polymers, in order to enhance the proton conductivity of $\mathrm{GO}$ with functionalities that are able to mimic the conduction mechanism of Nafion ${ }^{\circledR}$ and to favor a more homogeneous dispersion into polymer matrices $(4,7,9,11,14,17,18,20-22)$. Based on the promising results reported in literature $(4,11,18)$, this work is intended to be a proof of concepts about the development of freestanding sulfonated graphene oxide (SGO) membranes. Different samples have been produced by changing the amount of sulfuric acid used for the sulfonation reaction, since an optimal quantity is yet to be identified given the uncertainty in the knowledge of the exact structure of GO $(4,28)$. Then, these samples have been extensively characterized by FT-IR spectroscopy, TG-DTG analysis, optical microscopy; water uptake (WU), ion exchange capacity (IEC), degree of sulfonation and conductivity have also been evaluated, in order to study the consequences of the amount variation of sulfuric acid on the behavior of the prepared membranes. A pristine GO membrane has been prepared and characterized with the same methodologies, and the results have been compared with those obtained for SGO samples. Indeed, the main aim of this work is to analyze, at a preliminary stage, the effect of the amount of sulfuric acid in the sulfonation process of GO. Hopefully, results and findings of this research could be used as the starting point of a future and more systematic study aiming at determining the exact amount of acid needed for an effective sulfonation of GO to be used as an alternative electrolyte in PEM fuel cells.

\section{Experimental}

In order to prepare the pristine GO membrane as a benchmark, $100 \mathrm{mg}$ of $\mathrm{GO}$, in the form of a water-based solution ( $4 \mathrm{mg} / \mathrm{mL}$ commercial solution, supplied by Graphenea) were sonicated and then magnetically stirred for 3 hours at $650 \mathrm{rpm}$. Then it was vacuum filtered on a $0.22 \mu \mathrm{m}$ Millipore membrane filter placed into a Buchner funnel (29) and the cake was dried at $40{ }^{\circ} \mathrm{C}$ for 6 hours. A uniform self-assembled membrane was obtained

and physically characterized. Then, GO was sulfonated in order to investigate a possible enhancement of the proton conduction behavior. Sulfonated membranes (SGOs) were 
prepared by firstly mixing GO with variable contents $(30,3$ and $0.15 \mathrm{~mL})$ of sulfuric acid and then by magnetically stirring at $25^{\circ} \mathrm{C}$ and $650 \mathrm{rpm}$. After 3 hours, the solution was transferred into a round-bottomed flask which was immersed into an oil bath, connected to a reflux condenser and heated to $100{ }^{\circ} \mathrm{C}$ under stirring $(650 \mathrm{rpm})$, in order to favor the sulfonation reaction. The solution was then washed with variable volumes of deionised water to neutral, depending on the initial amount of the acid and the consequent $\mathrm{pH}$. Afterwards, such mixture was vacuum filtered and then dried for 24 hours at $80{ }^{\circ} \mathrm{C}$, obtaining the sulfonated membranes. The first amount of acid was selected on the basis of a literature reference (28). Actually, to the best of our knowledge, there is no precise idea about the proper amount of acid to be used for getting an effective sulfonation (4, 28). Moreover, most of the research works have not developed freestanding sulfonated GO membranes but rather have integrated or functionalized GO with proton conductive alkylbenzene sulfonates, oligomers or polymers through complex routes which employed mainly sulfanilic or chlorosulfonic acid (3, 6-9, 11, 12, 14, 15, 17-20, 22-24, 27, 28, 30$33)$.

On the basis of elemental analysis of the commercial GO dispersion employed, a tentative empirical formula $\left(\mathrm{C}_{1.5} \mathrm{H}_{0.2} \mathrm{~N}_{0.01} \mathrm{~S}_{0.03} \mathrm{O}\right)$ was determined and it allowed to calculate the molar ratio between $\mathrm{GO}$ and sulfuric acid. An acid volume of $30 \mathrm{ml}$ corresponded to a very high excess of acid (for SGO-1 membrane), therefore such ratio was tentatively reduced until reaching 1:1 for SGO-3 sample. Table I reports prepared samples, composition of the reaction mixtures and obtained membranes thicknesses.

TABLE I. Reaction mixtures composition and mean thickness values of the obtained membranes

\begin{tabular}{ccccc}
\hline Sample & $\begin{array}{c}\mathbf{m ~ G O} \\
{[\mathbf{m g}]}\end{array}$ & $\begin{array}{c}\mathbf{V ~ H}_{2} \mathbf{S O}_{\mathbf{4}} \\
{[\mathbf{m l}]}\end{array}$ & $\begin{array}{c}\mathbf{G O} / \mathbf{H}_{2} \mathbf{S O}_{\mathbf{4}} \\
{[\mathbf{m o l} / \mathbf{m o l}]}\end{array}$ & $\begin{array}{c}\text { Membrane } \\
\text { thickness [ } \boldsymbol{\mu m}]\end{array}$ \\
\hline GO & 100 & - & - & 41 \\
SGO-1 & 100 & 30 & 0.005 & 81 \\
SGO-2 & 100 & 3 & 0.05 & 47 \\
SGO-3 & 100 & 0.15 & 1 & 39 \\
\hline
\end{tabular}

The membranes surfaces were analyzed preliminarily by optical microscope (OM) and firstly characterized by Fourier Transform Infrared (FT-IR) spectroscopy and Thermogravimetric analysis (TGA-DTG) trying to analyze the effect of the reaction between GO and sulfuric acid for the different prepared samples. FT-IR was performed by Jasco-615 in the range $4000-400 \mathrm{~cm}^{-1}$; TGA was carried out by 6300 EXTAR 6000 SII Seiko Instruments in nitrogen atmosphere $(55 \mathrm{~mL} / \mathrm{min})$, with a linear heating rate of $10{ }^{\circ} \mathrm{C} / \mathrm{min}$ from $25^{\circ} \mathrm{C}$ to $1000{ }^{\circ} \mathrm{C}$.

The ion exchange capacity (IEC) of the membranes was measured through an acidbase titration technique (18). In a typical IEC experiment, a sample, previously dried for an hour in oven at $60{ }^{\circ} \mathrm{C}$, was immersed in $250 \mathrm{~mL}$ of $2 \mathrm{M} \mathrm{NaCl}$ solution at room temperature for $48 \mathrm{~h}$ to allow the exchange of $\mathrm{H}^{+}$with $\mathrm{Na}^{+}$ions. Then, the membrane was removed from the salt solution and the released $\mathrm{H}^{+}$ions titrated against $0.1 \mathrm{M}$ solution of $\mathrm{NaOH}$ using phenolphthalein as an indicator. By measuring the volume of consumed $\mathrm{NaOH}$, the molar quantity of ionic sites containing $\mathrm{H}^{+}$ions can be determined. The IEC, defined as milliequivalents (meq) of sulfonic groups per gram of dried sample, was obtained by the following equation: 


$$
\text { IEC }\left[\frac{\mathrm{meq}}{\mathrm{g}}\right]=\frac{\mathrm{V}_{\mathrm{NaOH}} \cdot \mathrm{C}_{\mathrm{NaOH}}}{\mathrm{W}_{\mathrm{dry}}}
$$

Where $\mathrm{V}_{\mathrm{NaOH}}$ is the volume $(\mathrm{mL})$ of $\mathrm{NaOH}$ consumed, $\mathrm{C}_{\mathrm{NaOH}}$ is the concentration $(\mathrm{mmol} / \mathrm{mL})$ of $\mathrm{NaOH}$ and $\mathrm{W}_{\text {dry }}$ is the weight of the dry membrane $(\mathrm{g})$. The IEC values were also used to calculate the degree of sulfonation (DS) for SGOs membrabes, by knowing the molecular weights of $\mathrm{GO}\left(\mathrm{MW}_{\mathrm{GO}}\right)$ and sulfonic group $\left(\mathrm{MW}_{\mathrm{S}}\right)(34)$ :

$$
\mathrm{DS}[\%]=\frac{\mathrm{MW}_{\mathrm{GO}} \cdot \mathrm{IEC}}{1000-\mathrm{MW}_{\mathrm{S}} \cdot \mathrm{IEC}} \cdot 100
$$

Water uptake experiments of the membranes were also performed. Before such tests, the samples were dried for two hours at $60{ }^{\circ} \mathrm{C}$, then put into a sealed bag to avoid adsorption of impurities or humidity and weighed $\left(\mathrm{W}_{\mathrm{dry}}\right)$. Then, they were placed for one hour into a humid chamber in which relative humidity had been fixed (around $80 \%$ ) and monitored by means of a hygrometer placed inside the chamber. Then the membranes were quickly wiped to remove possible excess of water and their wet weight ( $\left.\mathrm{W}_{\text {wet }}\right)$ measured. Water uptake (WU) percentage was calculated as follows:

$$
\mathrm{WU}=\frac{\mathrm{W}_{\mathrm{wet}}-\mathrm{W}_{\mathrm{dry}}}{\mathrm{Wdry}} \cdot 100
$$

The membranes resistance was preliminarily measured by the impedance spectroscopy (IS) technique using a 1260 Solartron Frequency Response Analyzer. Since part of the work is being still performed, we are going to present only measurements at room temperature and $50 \% \mathrm{RH}$ while a much deeper analysis about resistance and conductivity influenced by the change in both temperature and $\mathrm{RH}$ will be presented in a following paper. The membrane was placed into a lab-made cell between two steel electrodes having the same area. This assembly was then placed in a sealed-off glass cell specifically designed to be immersed in a thermostatic bath. Preliminary measurements were performed in dry conditions after flowing for four hours in the presence of a silica gel layer on the bottom of the conductivity cell and then RH was increased by using saturated salt solutions. IS was carried out under potentiostatic mode with a signal of 100 $\mathrm{mV}$ in the frequency range $100 \mathrm{kHz}-0.5 \mathrm{~Hz}$. Conductivity $(\sigma)$ was calculated according to the following equation:

$$
\sigma=\frac{\mathrm{L}}{\mathrm{R} \cdot \mathrm{S}}
$$

Where $\mathrm{S}$ is the electrode surface area $\left(\mathrm{cm}^{2}\right)$, orthogonal to charges movement, $\mathrm{L}$ is the distance between the electrodes $(\mathrm{cm})$ and $\mathrm{R}$ the measured internal resistance of the 
electrolytic membrane $(\Omega)$, i.e. the diameter of the semi-arc got as result from Nyquist plot (Figure 1).

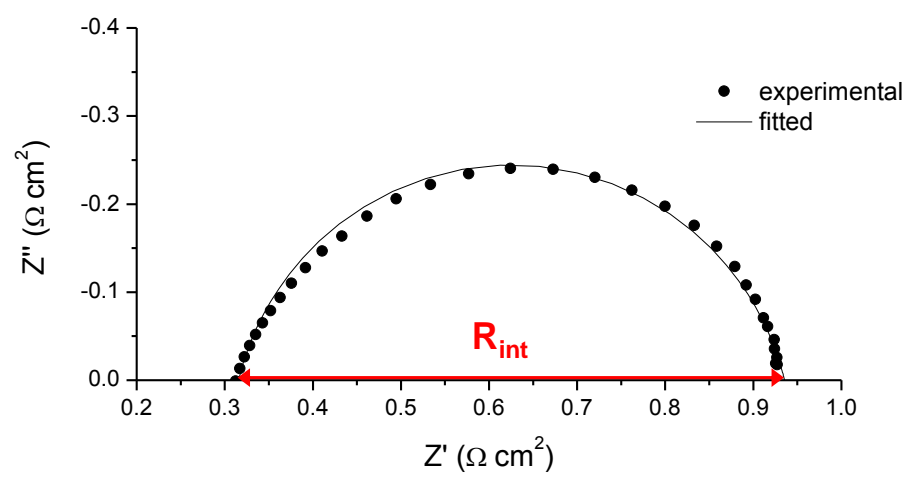

Figure 1. Example of a general Nyquist plot obtained from EIS for the measurement of membranes internal resistance

\section{Results and discussion}

Figure 2 shows the images of the produced membranes surface obtained by optical microscopy.

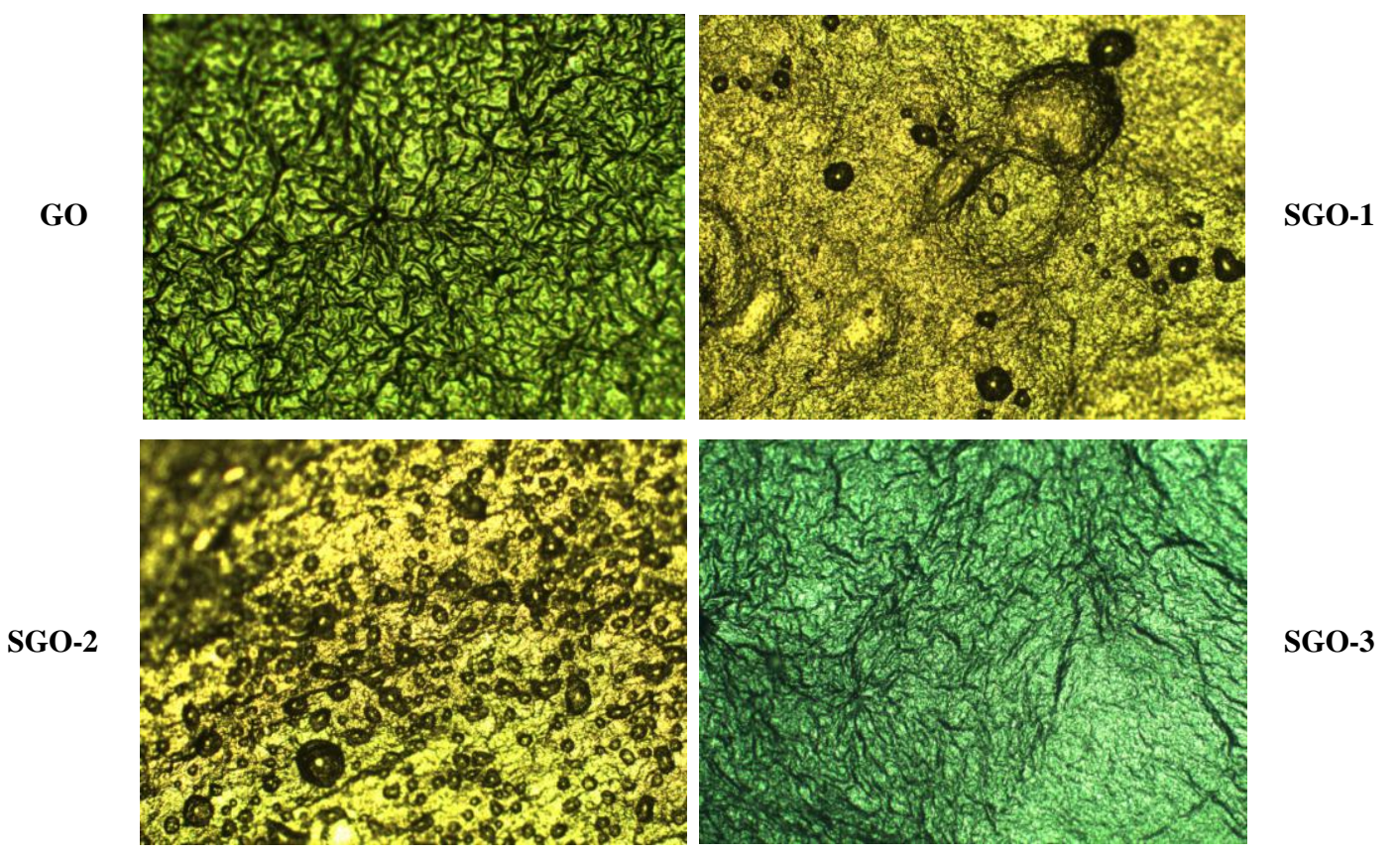

Figure 2. Optical microscope images of the prepared membranes, magnification of 100x 
Pristine GO membrane shows a uniform even though wavy surface which seems to be conserved only by SGO-3, maybe due to the lowest content of acid, i.e. with a 1:1 molar ratio $\mathrm{GO} / \mathrm{H}_{2} \mathrm{SO}_{4}$, used in the sulfonation process. On the contrary, samples SGO-1 and SGO-2, which have been obtained with a large excess of sulfuric acid, show more rough and uneven surfaces with 'bubble-like' defects, which are bigger for SGO-1, due to a probable effect of the higher amount of acid. From these images, it might be supposed that sulfonation process did not occur efficiently for SGO-3, since its surface is very similar to the pristine GO one with no evident holes previously ascribed to the action of sulfuric acid; such hypothesis will be confirmed by following figures and results.

Figure 3 shows comparison between FT-IR spectra obtained for pristine GO and sulfonated membranes.

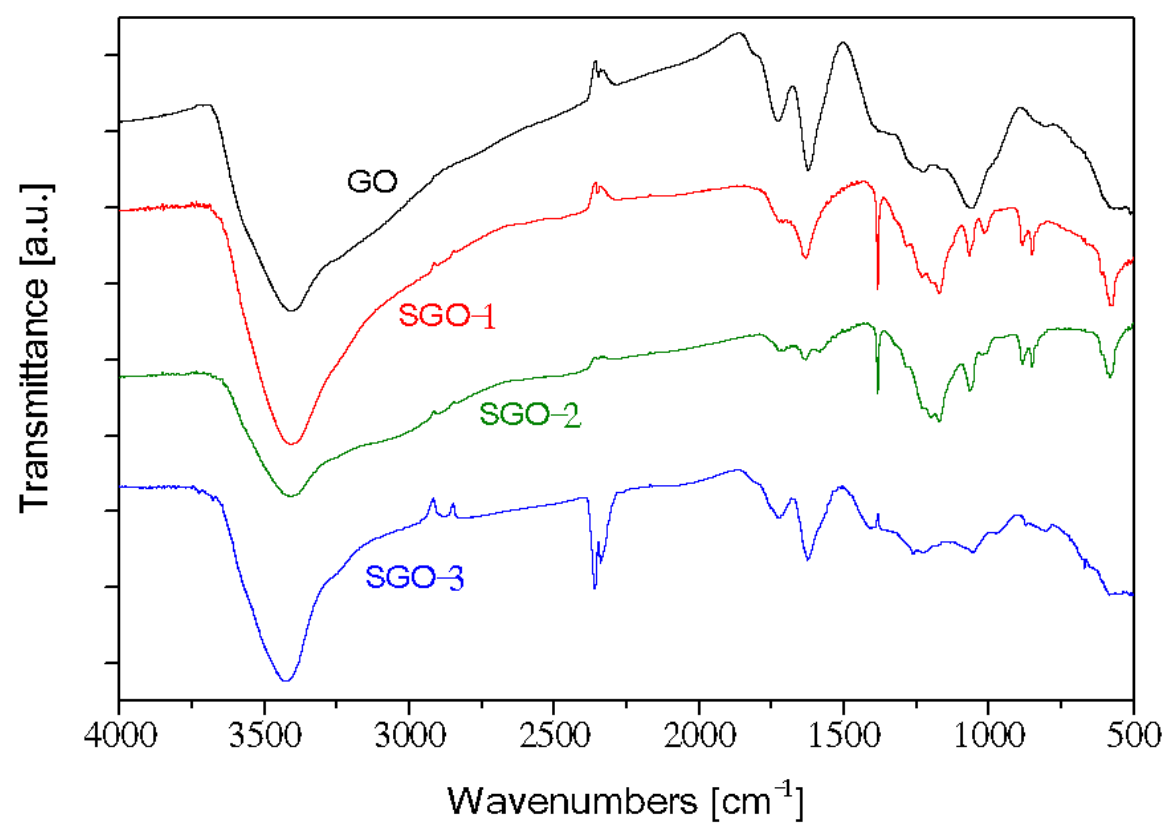

Figure 3. FT-IR spectra of the pristine GO and sulfonated membranes

FT-IR spectroscopy is a useful technique to assess the effectiveness of the sulfonation process. In the spectrum of pristine GO it is possible to point out all the characteristic peaks of GO. Characteristic absorption bands around 2363 and $3393 \mathrm{~cm}^{-1}$ can be respectively associated to the stretching of $\mathrm{CO}_{2}$ and of $\mathrm{O}-\mathrm{H}$ bonds of either intercalated water or hydroxyl groups. The peak at $1624 \mathrm{~cm}^{-1}$ can be related to $\mathrm{O}-\mathrm{H}$ bending while that at $1723 \mathrm{~cm}^{-1}$ can be ascribed to the stretching vibration of $\mathrm{C}=\mathrm{O}$ from carboxyl and carbonyl groups. At $1235 \mathrm{~cm}^{-1}$ and, more clearly, at $1064 \mathrm{~cm}^{-1}$ it is possible to find the stretching of epoxy group and of carboxyl group, respectively (29, 35). All these main functional groups can be also found in sulfonated samples which however evidence the presence of two important differences due to the reaction between $\mathrm{GO}$ and sulfuric acid. The sharp band at $1004-1324 \mathrm{~cm}^{-1}$ is the proof of absorption of $-\mathrm{SO}_{3} \mathrm{H}$ groups, since the peaks at $1004,1172,1286$ and $1324 \mathrm{~cm}^{-1}$ can be related to symmetric and asymmetric 
stretching vibrations of $\mathrm{S}-\mathrm{O}$ and of $\mathrm{O}=\mathrm{S}=\mathrm{O}$ bonds respectively $(15,17,20,24)$; they have been reported as well in the IR spectra of pristine Nafion found in literature $(36,37)$. The presence of such band seems to point out that the sulfonation of GO preferentially occurs on epoxide, hydroxyl and carboxyl groups, like proposed by $(7,8)$. Peaks around $575 \mathrm{~cm}^{-}$ ${ }^{1}$ can be associated to the C-S stretching, while the intense ones at $849-886 \mathrm{~cm}^{-1}$ can be related to the bending of either $\mathrm{C}=\mathrm{C}$ or $\operatorname{sp}^{2} \mathrm{C}-\mathrm{H}$ bonds $(12,22)$. All these bands are evident for SGO-1 and SGO-2 membranes, while they seems to disappear for SGO-3; the presence of a peak around $1250 \mathrm{~cm}^{-1}$, likely related to the stretching of $\mathrm{O}=\mathrm{S}=\mathrm{O}$ bonds, can be only glimpsed. Then, at 978 and $1058 \mathrm{~cm}^{-1}$ small peaks can be identified; they can be related to symmetric and asymmetric stretching vibrations of S-O or to those of C-O-C from epoxide bonds. Anyway, it seems that the amount of employed acid for the sulfonation process of SGO-3 membrane is not sufficient to allow the desired carbon ring functionalization.

Thermogravimetric analysis has been an important tool to confirm from a qualitative point of view the results of FT-IR about the sulfonation of GO. Figure 4 reports weight losses (a) and related derivatives (b) of all samples as a function of temperature.
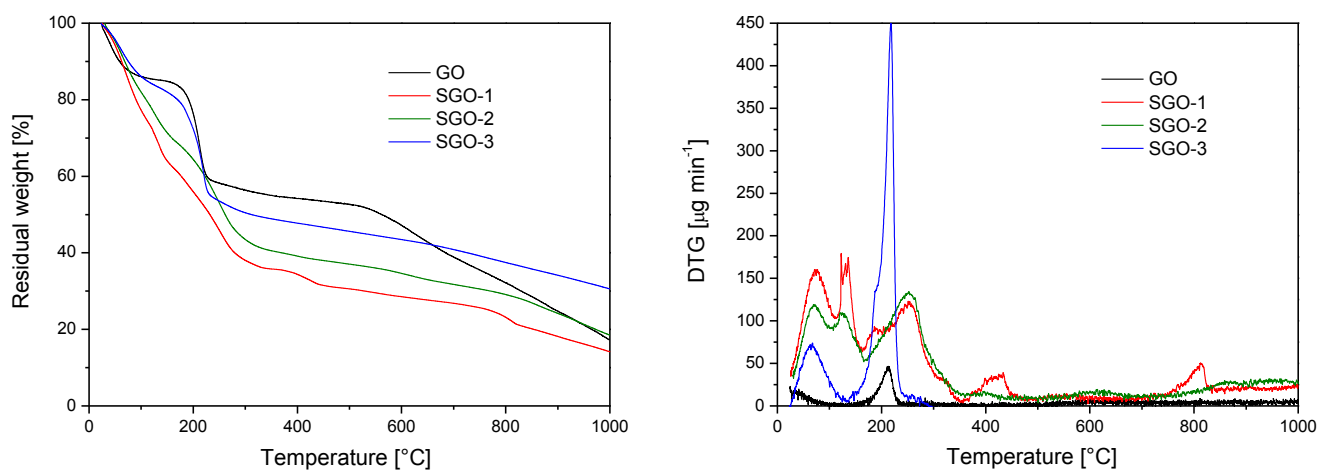

Figure 4. Results of TG and DTG analysis for all the prepared membranes

TG graphs can be divided in several parts, showing different behaviors depending on the extent of sulfonation. Firstly, a weight loss that is common to all samples can be noticed at low temperature (ca. $50-100{ }^{\circ} \mathrm{C}$ ); it is connected to the loss of water molecules physically adsorbed on hydrophilic groups. The second important weight loss lies in the temperature range of $100-140{ }^{\circ} \mathrm{C}$ and may be attributed to removal of the interlayer bound water (38); such contribution is more sharp for sulfonated membranes, especially for SGO-1 which has been obtained with the highest quantity of acid; this behavior is clearer by observing the peaks of DTG graph. So the weight losses associated to water molecules are more pronounced in sulfonated membranes, in particular for SGO1 and SGO-2, accounting for a more hygroscopic behavior. However, SGO-3 behavior is very similar to the one of pristine GO because of a too low amount of sulfuric acid used in the reaction step. The third weight loss shows a substantial difference between pristine GO and sulfonated ones: indeed the former exhibited a sharp loss in the range $140-215$ ${ }^{\circ} \mathrm{C}$, which can be related to the loss of oxygen-containing functional groups weakly bound to the framework (35); on the other hand weight losses for SGO-1 and SGO-2 extend to around $330{ }^{\circ} \mathrm{C}$ where decomposition of sulfonated groups weakly bound to the graphene oxide plane, as well as of residual oxygen-containing functional groups such as carboxyl, epoxy, hydroxyl and carbonyl can be predominant. Further losses, up to 500 
${ }^{\circ} \mathrm{C}$, can be correlated to decomposition of oxygen substituents strongly bonded to the main carbon molecule and to weakening of Van der Waals forces between the GO layers as well as to decomposition of sulfonated functionalities covalently bonded on GO, for SGO samples $(11,22)$; last losses $\left(500-1000{ }^{\circ} \mathrm{C}\right)$ should be related to the slow degradation of the carbon skeleton and to the destruction of the stacking layers both for pristine and for sulfonated GO.

The results of water uptake and IEC experiments as well as the values of degree of sulfonation (DS) calculated from equation (2) and preliminary conductivity obtained from EIS tests at room temperature and $50 \% \mathrm{RH}$ are reported in Table II.

TABLE II. Water uptake, IEC, DS and conductivity values obtained for pristine and sulfonated GO membranes

\begin{tabular}{ccccc}
\hline Sample & $\begin{array}{c}\text { WU } \\
{[\%]}\end{array}$ & $\begin{array}{c}\text { IEC } \\
{[\mathbf{m e q} / \mathbf{g}]}\end{array}$ & $\begin{array}{c}\text { DS } \\
{[\mathbf{\%}]}\end{array}$ & $\begin{array}{c}\boldsymbol{\sigma} \\
{[\mathbf{m S} / \mathbf{c m}]}\end{array}$ \\
\hline GO & 44.3 & 1.16 & - & 8.7 \\
SGO-1 & 45.7 & 1.26 & 5.1 & 8.3 \\
SGO-2 & 38.8 & 1.73 & 7.4 & 9.4 \\
SGO-3 & 29.8 & 0.95 & 3.7 & 2.2 \\
\hline
\end{tabular}

The measured water uptake values are similar to or slightly higher than the one obtained for commercial Nafion $(9,10,14)$. Compared to the other prepared membranes, SGO-3 shows a clear reduction of it. This behavior deserves for sure a deeper insight and further clarification but it is worth noting that such parameter might be influenced not only by hydrophilic functionalities but also by other variables such as porosity or roughness which are not strictly related to proton conduction mechanism. IEC values are similar for SGO-1 and SGO-2 and much lower for SGO-3. This can be due to the lower amount of the acid employed in the reaction step and could point out again that such quantity is not sufficient and proper for the desired functionalization. The highest value for IEC is shown by SGO-2 which should be due to a more efficient formation of sulfonic groups or C-S bonds compared to SGO-1. The obtained IEC values are higher than the one exhibited by Nafion (39), while in the reference (4), the only one which developed and characterized a freestanding sulfonated GO membrane for PEMFCs, a IEC of 1.1 $\mathrm{meq} / \mathrm{g}$ and a proton conductivity of $12 \mathrm{mS} / \mathrm{cm}$ were obtained; however, in the case of that reference, no precise information about the amount of sulfuric acid employed in the preparation step was given. It is also clear that higher values of IEC lead to higher degrees of sulfonation (DS) which in turn influence conductivity. Indeed, higher conductivities were found for higher DS values; for the sake of comparison, resistance of Nafion-212 has been measured and a conductivity of $7 \mathrm{mS} / \mathrm{cm}$ has been found. This should help in demonstrating at a very preliminary stage that a proper sulfonation is needed in order to increase the effectiveness of GO as a potential electrolyte alternative to Nafion.

\section{Conclusions}

This work is a preliminary feasibility study on the production of membranes based on graphene oxide (GO) to be used as potential alternative to Nafion at low humidity and 
hopefully at higher temperature in working PEM fuel cell systems. Both pure and sulfonated GO electrolytes were prepared very easily starting from an aqueous dispersion by exploiting the outstanding self-assembling properties of GO which is able to form uniform and mechanically resistant membranes. Since a precise stoichiometry between GO and sulfuric acid is not known yet, three tentative volumes of acid have been tried to functionalize GO carbon ring aiming to obtain a higher ion exchange capacity and a consequent better conductivity. A better behavior for GO and for some of the sulfonated membranes compared to Nafion in terms of ionic exchange capacity, water uptake and conductivity has been evidenced. However, we consider the obtained values as preliminary and, in a future work, trend of conductivity as a function of both temperature and RH will be reported for a deeper understanding of the effectiveness of the prepared self-standing membranes. Moreover, a more systematic analysis is also needed to determine precisely the optimal amount of sulfuric acid to be used in functionalization process for getting enhanced and reproducible performance.

\section{References}

1. F. Barbir, Sustain. World Ser., 1 (2005).

2. T. Bayer, S. R. Bishop, M. Nishihara, K. Sasaki and S. M. Lyth, J. Power Sources, 272, 239 (2014).

3. B. Zhang, Y. Cao, S. T. Jiang, Z. Li, G. W. He and H. Wu, J. Membr. Sci., 518, 243 (2016).

4. Ravikumar and K. Scott, Chem. Commun., 48, 5584 (2012).

5. T. Bayer, R. Selyanchyn, S. Fujikawa, K. Sasaki and S. M. Lyth, J. Membr. Sci., 541, 347 (2017).

6. X. Y. He, G. W. He, A. Q. Zhao, F. Wang, X. L. Mao, Y. H. Yin, L. Cao, B. Zhang, H. Wu and Z. Y. Jiang, Acs Appl. Mater. Inter., 9, 27676 (2017).

7. Z. J. Jiang, Z. Q. Jiang, X. N. Tian, L. J. Luo and M. L. Liu, Acs Appl. Mater. Inter., 9, 20046 (2017).

8. H. Zarrin, D. Higgins, Y. Jun, Z. W. Chen and M. Fowler, J. Phys. Chem. C, 115, 20774 (2011).

9. H. C. Chien, L. D. Tsai, C. P. Huang, C. Y. Kang, J. N. Lin and F. C. Chang, Int. J. Hydrogen Energ., 38, 13792 (2013).

10. Y. Kim, K. Ketpang, S. Jaritphun, J. S. Park and S. Shanmugam, J. Mater. Chem. A, 3, 8148 (2015).

11. M. Vinothkannan, A. R. Kim, G. G. Kumar and D. J. Yoo, Rsc Adv., 8, 7494 (2018).

12. Y. He, C. Y. Tong, L. Geng, L. D. Liu and C. Lu, J. Membr. Sci., 458, 36 (2014).

13. W. Gao, G. Wu, M. T. Janicke, D. A. Cullen, R. Mukundan, J. K. Baldwin, E. L. Brosha, C. Galande, P. M. Ajayan, K. L. More, A. M. Dattelbaum and P. Zelenay, Angew. Chem. Int. Edit., 53, 3588 (2014).

14. K. Feng, B. B. Tang and P. Y. Wu, J. Mater. Chem. A, 2, 16083 (2014).

15. K. J. Peng, J. Y. Lai and Y. L. Liu, J. Membr. Sci., 514, 86 (2016).

16. W. Jia, B. B. Tang and P. Y. Wu, Acs Appl. Mater. Inter., 9, 22620 (2017).

17. R. Kumar, M. Mamlouk and K. Scott, Rsc Adv., 4, 617 (2014).

18. M. Vinothkannan, R. Kannan, A. R. Kim, G. G. Kumar, K. S. Nahm and D. J. Yoo, Colloid Polym. Sci., 294, 1197 (2016). 
19. H. R. Jang, E. S. Yoo, R. Kannan, J. S. Kim, K. Lee and D. J. Yoo, Colloid Polym. Sci., 295, 1059 (2017).

20. C. X. Li, N. Huang, Z. Q. Jiang, X. N. Tian, X. S. Zhao, Z. L. Xu, H. Yang and Z. J. Jiang, Electrochim. Acta, 250, 68 (2017).

21. X. Qiu, T. D. Dong, M. Ueda, X. Zhang and L. J. Wang, J. Membr. Sci., 524, 663 (2017).

22. S. Gahlot, P. P. Sharma, V. Kulshrestha and P. K. Jha, Acs Appl. Mater. Inter., 6, 5595 (2014).

23. Y. X. Zhao, Y. Q. Fu, Y. He, B. Hu, L. D. Liu, J. H. Lu and C. L. Lu, Rsc Adv., 5, 93480 (2015).

24. S. L. Miao, H. Q. Zhang, X. B. Li and Y. Q. Wu, Int. J. Hydrogen Energ., 41, 331 (2016).

25. K. Kim, J. Bae, M. Y. Lim, P. Heo, S. W. Choi, H. H. Kwon and J. C. Lee, J. Membr. Sci., 525, 125 (2017).

26. C. Y. Tseng, Y. S. Ye, M. Y. Cheng, K. Y. Kao, W. C. Shen, J. Rick, J. C. Chen and B. J. Hwang, Adv Energy Mater., 1, 1220 (2011).

27. R. P. Pandey, A. K. Thakur and V. K. Shahi, Acs Appl. Mater. Inter., 6, 16993 (2014).

28. T. Cheng, M. N. Feng, Y. M. Huang and X. B. Liu, Ionics, 23, 2143 (2017).

29. A. Migliavacca, S. Latorrata, P. G. Stampino and G. Dotelli, Mater. Today-Proc., 4, 11594 (2017).

30. Z. Q. Jiang, Y. L. Shi, Z. J. Jiang, X. N. Tian, L. J. Luo and W. H. Chen, J. Mater. Chem. A, 2, 6494 (2014).

31. A. K. Mishra, N. H. Kim, D. Jung and J. H. Lee, J. Membr. Sci, 458, 128 (2014).

32. R. P. Pandey and V. K. Shahi, J. Power Sources, 299, 104 (2015).

33. A. Kausar, Int. J. Polym. Anal. Ch., 21, 537 (2016).

34. L. Unnikrishnan, S. K. Nayak, S. Mohanty and G. Sarkhel, Polym.-Plast. Technol., 49, 1419 (2010).

35. M. J. Fernandez-Merino, L. Guardia, J. I. Paredes, S. Villar-Rodil, P. SolisFernandez, A. Martinez-Alonso and J. M. D. Tascon, J. Phys. Chem. C, 114, 6426 (2010).

36. C. Korzeniewski, D. E. Snow and R. Basnayake, Appl. Spectrosc., 60, 599 (2006).

37. Z. X. Liang, W. M. Chen, J. G. Liu, S. L. Wang, Z. H. Zhou, W. Z. Li, G. Q. Sun and Q. Xin, J. Membr. Sci., 233, 39 (2004).

38. S. Bose and L. T. Drzal, Nanotechnology, 25 (2014).

39. R. Kannan, B. A. Kakade and V. K. Pillai, Angew. Chem. Int. Edit., 47, 2653 (2008). 